\title{
Historia de una biblioteca viva en una escuela rural. Un relato etnográfico
}

\author{
History of living library in a rural school. \\ An ethnographic account
}

\author{
Lucila Galván Mora, ${ }^{*}$ iana Solares Pineda, ${ }^{* *}$ Lydia Espinosa Gerónimo ${ }^{* * *}$
}

Recibido: 31 de mayo de 2021 Aceptado: 11 de julio de 2021 Publicado: 27 de julio de 2021

To cite this article: Galván, L., Solares, D. y Espinosa, L. (2021). Historia de una biblioteca viva en una escuela rural. Márgenes, Revista de Educación de la Universidad de Málaga. 2 (2), 57-71

DOI: http://dx.doi.org/10.24310/mgnmar.v2i2.12807

\section{RESUMEN}

Este artículo tiene el propósito de aportar conocimiento sobre la construcción social de las bibliotecas escolares en contextos rurales, sus usos pedagógicos y su potencial formativo. Se documenta una experiencia que entrelaza el currículum con la comunidad educativa, significada en la diversidad de un grupo multigrado y su entorno familiar y social. Se trata de un relato etnográfico sobre las posibilidades educativas de una biblioteca en una escuela rural mexicana, donde niños y niñas de distintas edades conviven y comparten historias que la maestra lee en voz alta, con el anhelo de sembrar el gusto por la lectura y la escritura en sus mentes y corazones infantiles. A pesar de carencias y abandonos, la escuela logra tener un rico acervo que los alumnos clasifican, cuidan y usan en beneficio propio. Se convierten en guardianes de los libros y las enseñanzas que esconden sus páginas. La biblioteca constituye un espacio cultural que genera posibilidades de intercambio y apertura al mundo para los alumnos y sus familias. Y sin duda ofrece alas para quienes emprenden el viaje del placer literario. El relato se basa en una investigación etnográfica sobre la diversidad de recursos pedagógicos que circulan en escuelas multigrado ubicadas en territorios rurales.

Palabras clave: grupo multigrado; biblioteca escolar; alumnos lectores; participación comunitaria

\section{ABSTRACT}

This article has the purpose of providing knowledge about the sociall construction of school libraries in rural contexts, their pedagogical uses and their training potential. An experience is documented that intertwines the curriculum, the educational community, signified in the diversity of a multigrado group and its family and social environment. It is an ethnographic account of the educational possibilities of a library in a rural Mexican school, where boys and girls of different ages coexist and share stories that the teacher reads aloud, with the desire to spread a taste for reading and writing I their children's minds and hearts. Despite deficiencies and dropouts, the school manages to have a rich heritage that students classify, care for and use for their own benefit. They become guardians of the books and teachings behind their pages. The library constitutes a cultural space that creates possibilities for exchange and openness to world for students and their families. And it certainly offers wings for those who undertake the journey of literary pleasure. The story is based on ethnographic research on the diversity of pedagogical resources that circulate in multigrado schools located in rural territories.

Keywords: group multigrado; school library; reading students; community participation

"Lucila Galván Mora

0000-0002-5146-2286

Investigadora independiente. Miembro de la Red Temática de Investigación de Educación Rural (RIER) (México)

lucila_galvan@yahoo.com.mx
**Diana Solares Pineda 0000-0001-6034-6693

Profesora e investigadora de la Universidad Autónoma de Querétaro. Miembro de la RIER (México) violetasolares@gmail.com

\author{
***Lydia Espinosa Gerónimo \\ 0000-0001-6034-6693 \\ Asesora en Oficina de Programa de \\ Gobierno del Estado de Veracruz. \\ Miembro de la RIER (México) \\ clydiaespinosageronimo@yahoo.fr
}




\section{PRESENTACIÓN}

En este artículo narramos la historia de Mente y corazón viajeros, una biblioteca que floreció en una escuela rural mexicana, a pesar de muchas dificultades y no pocas carencias. Los alumnos, niños y niñas que tenían entre seis y doce años de edad, son los protagonistas indiscutibles. Juntos atravesaron un camino de tiempo que los llevó a ser guardianes de los libros, lectores ávidos y hacedores de textos cotidianos. Juntos descubrieron, como quería su maestra, la magia de la literatura.

Se trata de un relato derivado de una investigación etnográfica que realizamos en una escuela unitaria de Veracruz, en México, entre los años 2011 y 2016, con el fin de documentar prácticas pedagógicas vinculadas a la enseñanza de la lengua escrita en grupos multigrado.

Los propósitos que perseguimos con este artículo son amplios y responden al interés de pensar las posibilidades de innovación de la escuela en nuestros territorios rurales:

a. Aportar conocimiento sobre la construcción social de las bibliotecas escolares en comunidades rurales, sus usos pedagógicos y su potencial formativo.

b. Promover la reflexión sobre el aporte de las bibliotecas en el aprendizaje de la lengua escrita y los valores para la civilidad.

c. Debatir el estereotipo de precariedad que suele opacar la fecundidad de las escuelas multigrado y sus bibliotecas.

Desde la realidad local de una escuela rural, preguntamos sobre el qué, el para qué y el cómo de la biblioteca escolar, con la intención de contribuir a la "cartografía inconclusa" que aún existe sobre los usos y alcances de este espacio en los centros escolares de América Latina (Robledo, 2014).

En primer lugar, como preámbulo, presentamos “Mente y corazón viajeros”, un relato etnográfico de los hechos más relevantes que dan cuenta de la fundación y el devenir de una biblioteca escolar. Es una interpretación entre otras posibles, sostenida en una discusión teórica sobre las posibilidades formativas que pueden generar los afanes bibliotecarios. El corte literario del relato pretende que la historia sea accesible y amena para un público amplio y diverso.

En el segundo apartado abordamos aspectos concernientes a la "Metodología” que seguimos para construir el relato, y algunas decisiones que tomamos para su presentación. Describimos brevemente las etapas de trabajo de campo y las implicaciones analíticas de la estrategia narrativa que elegimos.

En el tercer apartado denominado "Aproximación a las condiciones básicas de una biblioteca viva”, exponemos a manera de discusión algunas condiciones que advertimos indispensables para impulsar la vitalidad pedagógica de las bibliotecas escolares, basadas principalmente en el análisis del relato que compartimos. Por último encontrarán "Una reflexión final” sobre las posibilidades de la escuela y su biblioteca para construir ciudadanía en comunidades rurales. 


\section{MENTE Y CORAZÓN VIAJEROS}

Para Juan David

Que partió a su galaxia

Estrellita llegó al aula en invierno.

Un día de enero frío y seco. Fueron los niños y las niñas del grupo, reunidos en asamblea, quienes pusieron nombre a esa pequeña tortuga, jaspeada y vivaz. Lo eligieron entre varios con una apretada votación: Manchita, Arcoíris, Mariposa y Capita fueron desechados ante la abrumadora preferencia por el astro que, en adelante, prestaría fulgor a su mascota.

Ese mismo día los alumnos conformaron equipos para atender a la tortuguita en el aula, y decidieron la ruta que seguiría por las casas familiares, los fines de semana, cuando la escuela permanecía cerrada. Todos los niños sin excepción, grandes y pequeños, serían responsables de alimentarla y protegerla. Aprenderían, anticipó la maestra, a cuidar con esmero a un ser vivo.

Un nutrido aplauso, acompañado de gritos y saltos de júbilo, acogió a la nueva integrante del grupo. La calidez del ambiente escolar contrastaba con el gélido entorno invernal. ¡Era todo un festejo de bienvenida! Pero ni la maestra ni sus alumnos vislumbraron entonces que Estrellita sería compañera inseparable en el largo camino que recorrerían para llegar a ser niños bibliotecarios, lectores gozosos.

La escuela se encuentra en Mundo Nuevo.

Un pueblo veracruzano con intenso tránsito migratorio. En los tiempos del relato, los padres de varios alumnos eran jornaleros estacionales, iban y venían siguiendo los ciclos de siembra y cosecha de varios productos: café, caña, tomate, piña o naranja. Solían ausentarse largas temporadas, llevando consigo a los niños mayores para que ayudaran en las faenas. Así que el grupo escolar crecía y decrecía constantemente, al acorde del vaivén nómada.

Diez niños y ocho niñas entusiastas, inquietos y con ojos brillantes, conformaban el único grupo de esa escuela rural. Tenían edades disímiles, entre los seis y los doce años; inscritos en diferentes grados, aprendían y crecían juntos. Compartían el espacio del aula, tareas y responsabilidades. Por supuesto también compartían a la maestra Lydia, quien atendía a todos simultáneamente. Ella hacia malabares para mantener "al corriente" a los alumnos ausentes, y receptivos a quienes permanecían en el aula. Quería que todos concluyeran la educación primaria, a pesar de las difíciles condiciones que enfrentaban algunos.

Esta escuela rural, como muchas en nuestro país, carecía de mobiliario y materiales adecuados para las actividades educativas. De hecho, había permanecido cerrada siete años, hasta que una Agente Municipal y varias madres de familia, se empeñaron en su rescate. La maestra Lydia aceptó laborar en la localidad, y juntas enfrentaron problemas y burocracia para volver a abrir el centro.

Los años de clausura hicieron que la escuela desapareciera prácticamente de las estadísticas oficiales y no fuera considerada en programas para mejora de infraestructura, suministro de materiales o dotación de acervos. Era una escuela invisible, inexistente para la administración. 
Abandonada, desprovista de barda, ventanas, agua, luz, mobiliario, mapas, libros... la escuela era una sombra. Una incongruencia absoluta del discurso político que proclamaba inclusión, equidad y calidad educativas para las comunidades rurales.

¡Todo estaba por hacerse!

Para la maestra, la apertura de la escuela representaba prácticamente una "refundación”. El centro tenía que "levantarse" prácticamente de los escombros, lo que significó para ella y la comunidad una aventura sin regreso. Las madres de familia se organizaron y con ayuda de algunos señores, "chapearon" la maleza que había invadido el predio. Recogieron las piedras del patio, lavaron y pintaron el aula, colocaron cristales en las ventanas e improvisaron un baño. Deseaban que los niños y las niñas pudieran estudiar y jugar a gusto, sin correr riesgos innecesarios.

Apoyaron los trámites de la maestra para legalizar el terreno escolar, donado de palabra por la madre fallecida de un terrateniente, preocupada por la escolaridad de los hijos de los jornaleros. La escritura formal era necesaria para obtener financiamiento y construir espacios nuevos: otra aula, la barda perimetral, baños adecuados y un pequeño comedor escolar.

Dentro del aula existente se dispuso un rincón para la biblioteca. Esquinados, se acomodaron algunos "huacales" a modo de libreros y se colocó una mesa para el trabajo en equipo. No había libros y, después de arduas gestiones, la maestra logró que la Coordinación Estatal de Bibliotecas asignara una dotación incompleta de ejemplares, como dádiva emergente mientras la escuela volvía a formar parte del padrón escolar, lo cual llevaría varios meses.

Ante esta situación, la maestra pidió a familiares, colegas y amigos que donaran libros para sus alumnos. Y los aportes llegaron de manera inmediata y nutrida. Pronto los libros poblaron el aula, los "huacales" que servían de estantes lucieron títulos diversos y la biblioteca poco a poco cobró vida.

La maestra tenía un anhelo en el corazón.

Quería que sus alumnos descubrieran la magia de la lengua escrita, y no dudó en desplegar esfuerzos para conseguirlo. Impulsó diversas actividades para fomentar la lectura colectiva de cuentos o anécdotas que los niños y niñas elegían previamente. Ella leía en voz alta, mientras los alumnos, sentados en círculo, seguían la trama con interés, asombro, expectación y placer.

En la jornada diaria, siempre había momento para la lectura compartida. A veces, se necesitaban varios días para terminar un relato. Entonces los niños seguían el hilo día con día, hasta llegar al fin. En estos casos, si alguno de ellos faltaba, pedían a la maestra no continuar la lectura, para que nadie perdiera fragmento alguno. Petición unánime que quedó inscrita en el contrato didáctico del grupo.

Una canasta llena de libros circulaba por el aula y las áreas del patio que los niños y niñas solían ocupar. Era un hermoso objeto móvil, una extensión de la biblioteca que impregnaba dinamismo a las actividades escolares, donde fuera que éstas se realizaran. La canasta de libros, al decir de la maestra, estaba al servicio de los niños. Iba al lugar donde ellos se encontraran, cuando los afanes infantiles la necesitaban. 
Integró además el Grupo Alfa con alumnos de primero y segundo grados en proceso de alfabetización inicial, para construir textos colectivos que ella escribía en la pizarra, a la vez que iba señalando reglas y convenciones gramaticales. Las vivencias y andares de esos niños por la escuela, la casa y la localidad, alimentaban los escritos, afianzando tempranamente el gusto por el texto libre y cotidiano.

La maestra concibió el Grupo Alfa como espacio de creación literaria para los alumnos que tuvieran deseos de escribir en colaboración. En su visión, este grupo era flexible, estaba abierto para todos, sin importar la edad, el grado escolar o el avance alfabético de cada quien. Constantemente, los alumnos de grados superiores se integraban al colectivo, cuando querían un refugio para escribir.

¡Sorpresa!

Una mañana llegó a la escuela un regalo trasatlántico. Emergió de una bolsa de papel, ante la mirada expectante de todos. Se trataba de Escúchame el corazón, la novela que Bianca Pitzorno publicó con el sello de Sabina, en el año de 2008. Un relato entrañable sobre las aventuras de Prisca, su tortuga Dinosauria y su amiga Elisa, que trascurre en Cerdeña, en la época de la posguerra, en una escuela primaria a la que acudían las dos niñas. Juntas enfrentaron a la injusta maestra Argia Sforza, se opusieron a la grotesca discriminación que las niñas pobres sufrían en el aula y compartieron los sinsabores del primer enamoramiento. Prisca quería ser escritora y narraba historias de las personas que conocía, exponiendo vida y amores de vecinos y familiares. A veces — aseguraba — se permitía alguna licencia poética.

Las 348 páginas de la novela fueron leídas por la maestra Lydia a lo largo de un ciclo escolar. Niños y niñas siguieron con interés los pasos de Prisca y su traviesa, valiente tortuga. La imaginación infantil volaba al paso de las páginas y los niños más pequeños se asombraban al percatarse de las escasas ilustraciones que contenía el libro ¿Cómo era posible tanta fantasía?, parecían preguntarse. Descubrían el poderío de la palabra escrita.

Ante la llamarada de entusiasmo que despertó la novela, la maestra propuso a los alumnos que elaboraran cartas, mensajes y dibujos, como obsequios para enviarlos a Bianca, a Milán, donde vivía la autora. La respuesta no se hizo esperar y se inició una prolífica producción literaria en el grupo: cuentos, cartas, recados y anécdotas que aludían a escenas de la novela.

En la versión infantil las tortugas eran amigas para "siempre jamás”. En algunos dibujos se podía ver a Estrellita y Dinosauria contemplando juntas el atardecer a la orilla del mar, nadando con peces de colores mientras las olas cubrían de espuma sus caparazones, camufladas con piedras y hojarasca o corriendo a toda velocidad en el patio escolar, rodeadas de niños. Ambas tenían un hermoso terrario que compartían a pesar de la distancia, en cuya arena descansaban de juegos y correrías.

Durante meses, los textos y dibujos infantiles se acumularon en un gran sobre amarillo cuyo remitente no dejaba lugar a dudas: "Para Bianca”, decía. Cuando el sobre llegó a manos de la autora, los alumnos ya habían terminado la novela y estaban preparando la presentación del libro en una galería de arte, ubicada en Xalapa, ciudad capital del estado. Para la ocasión, con 
ojo crítico, seleccionaron algunos dibujos para exponerlos en la sala principal del recinto, cuyos autores ampliaron y pulieron con esmero.

Bianca recibió con emoción la noticia de que su novela había sido leída en una pequeña escuela rural mexicana. ¡Y que su libro fuera presentado por dos niñas, la llenaba de orgullo! Adivinaba un vínculo epistolar con esos alumnos, lectores ávidos y agradecidos. Conmovida, envió al grupo otro regalo nacido de su invención. Un cuento maravilloso donde los principales personajes eran los niños y niñas de esa escuela, Estrellita y la maestra de todos.

El acervo creció considerablemente.

Gracias a las donaciones y la compra de libros que eventualmente hacia la maestra. Creció tanto, que ella consideró había llegado el momento de un pasaje trascendental para los alumnos: dejarían de ser solo usuarios de la biblioteca para convertirse en "alumnos bibliotecarios”. Apreciar, cuidar y organizar los libros eran saberes que todos cultivarían en su paso por la escuela.

En primer lugar, los alumnos identificaron las secciones de la biblioteca y asignaron un color a cada una, en función del tipo de texto que contenía: amarillo para novela por capítulos, verde para cuento, azul para historias con moraleja, y así...

Las señoras que integraban el Consejo Escolar de Participación Social y el Voluntariado de la comunidad ayudaron a enumerar los libros progresivamente y colocar en su lomo una mota de color, indicativa de la sección a la que pertenecían. Durante varias tardes, levantaron el inventario de libros y revistas que resguardaba la biblioteca. Y, una vez concluido, acomodaron los libros en los "huacales" que hacían de estantes, de forma tal que todos los niños podían acceder fácilmente al ejemplar de su preferencia.

Los alumnos asumieron múltiples tareas para mantener ordenado y completo el acervo. Antes que nada, establecieron cargos para controlar el préstamo de libros: Responsable General, Responsable de Sección y Ayudantes. Elaboraron credenciales para ellos y su maestra; así como para algunos exalumnos que, inscritos en la secundaria de una localidad cercana, visitaban la escuela primaria y solicitaban libros en préstamo. Incluyeron también a madres, padres y tutores que, a veces, llevaban revistas a su casa. Los prestamos eran autorizados por la niña que fungía como Responsable General, estampando su firma en las credenciales de los usuarios.

Como medida complementaria, la maestra sugirió que en la portadilla de los libros se imprimiera un sello con el nombre y la clave del centro, como prueba irrestricta de propiedad de esa escuela rural.

¡No sabía a dónde me iban a llevar los “peques”!

Exclamaba la maestra al recordar que cuando inició la lectura de la novela no tenía una ruta didáctica trazada, aunque sí una clara intención pedagógica. Dejó que los intereses infantiles encauzaran las actividades escolares; y sobre la marcha fue diseñando estrategias para la enseñanza de la lengua escrita, ajustando los aprendizajes esperados para cada alumno, tomando decisiones para abordar contenidos gramaticales en función de sus necesidades particulares. 
Entre todos construyeron un trayecto de aprendizaje. Elaboraron una lista de palabras que no conocían, como "tembleque”, "palurda”, “ciclamen”, "soplamocos”; y buscaron en el diccionario sinónimos y significado. Escribieron cuentos e hicieron dibujos donde Prisca, Elisa y las tortugas, amigas todas, eran protagonistas. Narraban aventuras, juegos y algunos pesares de escuela. Después, frente a los padres y madres de familia, en reuniones especiales, niños y niñas leían en voz alta los textos que habían creado usando "palabras nuevas", provocando el asombro de sus progenitores.

La maestra quería que sus alumnos culminaran el camino recorrido con una experiencia extraordinaria. Y fue entonces que propuso presentar Escúchame el corazón fuera de la escuela, en la Galería de Arte Contemporáneo de Xalapa, un espacio cultural abierto al público. Las madres y padres de familia manifestaron beneplácito frente a la iniciativa de la maestra y tomaron previsiones para apoyar a los niños y asistir al evento.

Como era usual en el grupo, en una asamblea se eligieron los textos que serían leídos en la presentación, los mejores según el criterio infantil. Abril y Lupita, ambas con nueve años y en $4^{\circ}$ grado, fueron las niñas distinguidas. En sus textos se referían a los pasajes de mayor impacto para ellas: la lucha de Elisa y Prisca contra una maestra abusiva y discriminadora, la amistad que unía a esas dos niñas, la fuerza de sus convicciones y su afán de justicia. También aludían a la amistad de Estrellita y Dinosauria, a su imaginado encuentro en un lugar remoto del mundo.

La presentación del libro fue un éxito rotundo.

Asistieron todos los niños y niñas del grupo, ocupando un lugar preferente. Las madres, padres y personas de la comunidad hicieron acto de presencia, emocionadas por el acontecimiento. Acudieron también maestros rurales colegas de la maestra, estudiantes de magisterio y docentes de una escuela normal; y autoridades educativas de alto nivel. Por supuesto, también asistió Estrellita que, desde el cristal de su pecera colocada sobre el escenario, miraba perspicaz al público asistente.

La voz de las niñas presentadoras se escuchó clara y firme. Estaban preciosas, peinadas con trenzas y lazos de seda. Junto a ellas, la maestra Lydia recibía las hojas que iban leyendo; su cercanía ofrecía seguridad y confianza a ambas, que por primera vez exponían frente a un auditorio diverso. Apoyadas, las dos niñas salieron airosas de ese desafío literario.

También se escuchó la voz de Bianca, con la lectura pública del cuento que envió desde Milán para la ocasión. En la historia, todos los niños y niñas viajan con su maestra y su pequeña tortuga en un barco de vela. Conocen islas habitadas por indígenas, piratas que tocan violín y astrónomos de barba larga y blanca. Por el ojo de un ciclón llegan a una galaxia desconocida cuyas estrellas, anónimas, fueron bautizadas con el nombre de cada uno, de cada una: estrellas Iris, William, Rey David, Erik y Demián; estrellas Celia, Jorge, José Antonio, Abril y Guadalupe; estrellas Víctor, Citlalli, Joatam Elías, Brenda, Sarita, Dulce Vanessa y Ángel. ¡Y estrella Juan David!

Luego, trasportados por la lluvia celeste de agosto, todos caen en la terraza de la casa que habita la autora, quien los recibe con dulces italianos muy ricos, mientras Dinosauria y Estrellita, felices por conocerse, se dan muchos besitos. Pero el cuento no termina ahí, el viaje seguirá por lugares inexplorados, solo que ahora son los niños y niñas quienes deberán continuar el relato 


\section{N V E S T I G A C I O N E S}

con las alas de su imaginación. En tanto, Bianca aguarda con ilusión la saga de la historia, mientras acaricia con parsimonia el gato de sus vecinos.

¡Los libros tuvieron, por fin, una habitación propia!

Un año después de la presentación del libro, gracias a la intervención decidida de la directora de la galería de arte, la escuela fue sujeto de financiamiento y se construyó un "salón de usos múltiples”, donde se colocaron estantes rodantes, mesas, archiveros y computadoras. En ese espacio se instaló la biblioteca. La gestión fue un reconocimiento a la dedicación y arrojo de ese puñado de niños y niñas que, a través de la literatura, trascendieron los confines de su mundo habitual. La maestra, emocionada, impulsó entonces un proyecto para la inauguración del nuevo recinto, que la comunidad entera acogió como propio. Mientras que los alumnos, reunidos nuevamente en asamblea, bulliciosos pero con la seriedad que ameritaba el evento, decidieron el nombre que llevaría su biblioteca: "Mente y corazón viajeros”.

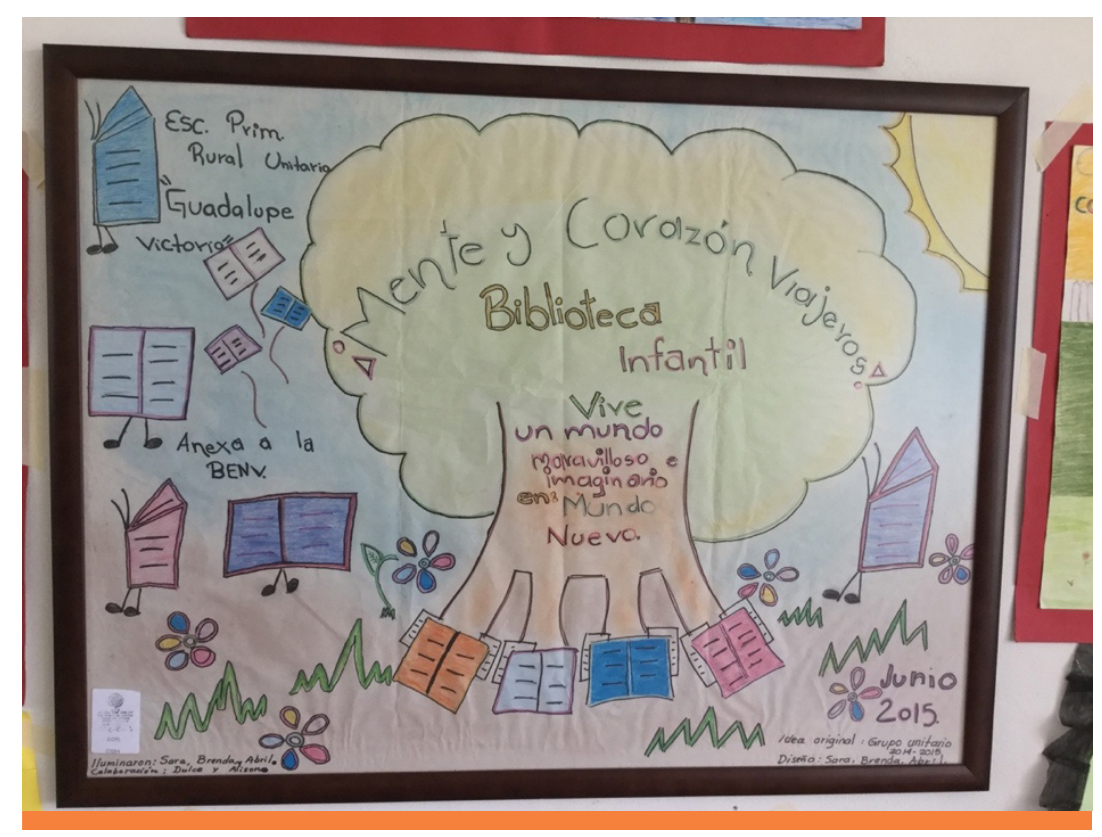

Figura 1. Obra infantil colectiva. Nota. Archivo etnográfico propio

\section{METODOLOGÍA}

\section{Antecedentes}

El relato deriva de una investigación etnográfica que realizamos en la escuela primaria de Mundo Nuevo, durante dos periodos. El primero, abarcó los años de 2011 y 2012, cuando avanzamos un proyecto que tuvo el propósito de documentar prácticas y saberes docentes en escuelas multigra- 
do de Veracruz ${ }^{1}$. Hicimos visitas sistemáticas a la escuela y realizamos observaciones de clases, asambleas infantiles y reuniones con madres de familia. Elaboramos "versiones ampliadas" de los registros de campo ${ }^{2}$ y empezamos a integrar el archivo etnográfico de la escuela.

De esta época data la asamblea donde los alumnos eligieron el nombre Estrellita para su tortuga. De hecho, fue el primer evento escolar que observamos, con el acuerdo de la maestra y el consentimiento de los niños y niñas. Entonces no imaginamos que el registro de este suceso sería punta de lanza del relato que tienen en sus manos; la apertura de una reflexión sobre los usos pedagógicos de la biblioteca en escuelas rurales y su significado para la vida de los alumnos.

El segundo periodo trascurrió entre los años 2015 y 2016 y consistió en un estudio de caso múltiple que contempló a la escuela primaria mencionada, más un aula preescolar y una telesecundaria; todas escuelas unitarias, ubicadas en territorios rurales con alto grado de marginación. En esta ocasión, los propósitos fueron identificar estrategias didácticas innovadoras vinculadas a la enseñanza de la lengua escrita en contextos multigrado, y elaborar un inventario de recursos pedagógicos presentes en las aulas ${ }^{3}$.

Durante esta indagación advertimos la importancia que los docentes otorgaban a la biblioteca escolar, como recurso privilegiado para incentivar la alfabetización inicial o la consulta bibliográfica, el uso de convenciones gramaticales o el gusto por la literatura, según las necesidades de los alumnos. A pesar de la flacura de algunos acervos - como el que tenía la telesecundaria-, en torno a las bibliotecas se generaba una intensa actividad escolar que implicaba a los alumnos y a sus familias; y los docentes promovían sin descanso el aprecio por los libros (Galván, Solares y Espinosa, 2018).

En este segundo periodo tuvo lugar la inauguración del recinto que albergó a la biblioteca “Mente y corazón viajeros”, en la escuela de Mundo Nuevo. Evento importante para toda la comunidad, que ese día desbordó la escuela. Habían pasado cinco años desde que Estrellita llegó al aula, y dos desde la presentación del libro (Pitzorno, 2008) en la galería de arte. No obstante el tiempo trascurrido, estos hechos formaban parte del presente de la biblioteca.

Las paredes del nuevo salón lucían aquellos dibujos que los alumnos expusieron en el vestíbulo de la galería. Y frente a ellos, contemplándolos, nos dimos cuenta que teníamos la responsabilidad de contar la historia de esa biblioteca viva, para contribuir a preservar la memoria colectiva de esa escuela rural.

\footnotetext{
1 Este proyecto se denominó "Saberes docentes y prácticas innovadoras en escuelas multigrado anexas a la Benemérita Escuela Normal Veracruzana (BENV)", y fue financiado por esta misma institución.

2 Las "versiones ampliadas" de los registros de campo se refieren a temas específicos relacionados con la investigación. Incorporan datos recogidos en observaciones in situ, realizadas en el aula u otros espacios escolares; fragmentos de entrevistas o conversaciones, ya sea grabadas o reconstruidas con las notas; así como información proveniente de diversas fuentes como programas de estudio, libros de texto, reglamentos, planeaciones, cuadernos de los niños, periódicos murales y pizarras, entre otros. Se complementan, además, con fotografías o video grabaciones relacionadas con los eventos registrados.

3 Este estudio se llevó a cabo por iniciativa de la RIER en cuatro entidades del país: San Luis Potosí, Tabasco, Veracruz y Zacatecas. Véase algunos resultados en Cano e Ibarra (2018).
} 


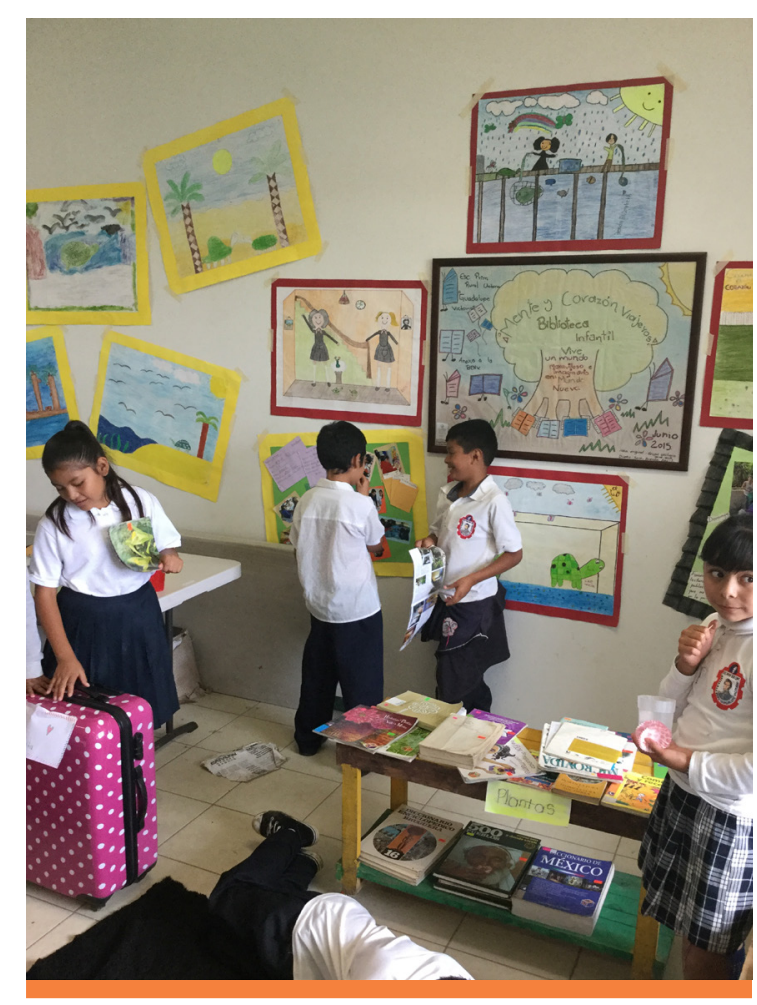

Figura 2. Dibujos infantiles en la biblioteca. Nota. Archivo etnográfico propio

\section{Información de campo y su análisis}

La construcción del relato supuso un trabajo teórico previo. En la revisión de la literatura sobre el tema, identificamos la preocupación de algunos autores que preguntan sobre el papel de las instituciones educativas en la sociedad actual, donde "abunda la información y escasea el conocimiento"; e inquieren sobre los aportes de las bibliotecas en la formación de una ciudadanía "plena y democrática” (Bonilla, Goldin y Salaberria, 2014, pág. 3-4). Y coincidimos, además, con la concepción de las bibliotecas como "espacios de posibilidad” (Castán, 2014) para combatir la exclusión y el fracaso escolar desde las aulas.

De esta manera, formulamos preguntas que, comprometidas con el tema de interés, fueran más allá de la dimensión local:

¿Cuáles son los alcances educativos de las bibliotecas escolares?

¿Qué significados tienen para la innovación de las escuelas rurales?

¿Cómo contribuyen en la construcción de la cultura escrita?

¿Cuál es su contribución para la formación de la ciudadanía?

Nuestra mirada interrogó, desde el principio, sobre los usos pedagógicos de la biblioteca en el “contexto doméstico" (Geertz, 2005) de una escuela rural; e indagó además sobre los alcances educativos que este ámbito puede tener en un territorio con elevados índices de marginación, donde el aprendizaje de la lengua escrita, para los alumnos y las familias, constituye una ventaja importante para una participación social más equitativa en el complejo mundo de hoy.

Con esta base conceptual, establecimos cinco categorías para orientar la exploración que emprendimos por los archivos de campo. A partir de ellas distinguimos datos relevantes, organizamos la información recuperada y seleccionamos los eventos relacionados con la biblioteca que interesaba mostrar. En términos metodológicos, las categorías propuestas perfilaron el contenido empírico del relato y funcionaron como ejes analíticos para estructurar la narración.
a. Condiciones y características de la biblioteca escolar
b. Usos pedagógicos del acervo
c. Estrategias de enseñanza relativas a la lengua escrita
d.Estructuras de participación de los alumnos
e. Vinculación comunitaria 
La historia de la biblioteca, que compartimos en este artículo, recupera información de 9 versiones ampliadas de registros de campo, elaboradas durante los dos periodos de investigación ya señalados ${ }^{4}$; así como anécdotas de la novela escrita por Bianca Pitzorno, y pasajes del cuento que ella elaboró para los alumnos, como agradecimiento por su lectura atenta y entusiasta. Recobra, además, textos de diversas fuentes, tanto de los alumnos - cuadernos, dibujos, cartas, mensajes, papelógrafos—, como de la maestra — planeaciones, anecdotario, agendas, ruta de mejora de la escuela_-, con la idea de que la voz de los principales protagonistas sea escuchada.

En el relato, procuramos una secuencia apegada al devenir de los acontecimientos registrados, toda vez que, en este caso, el trascurso del tiempo resulta de especial importancia para mostrar la evolución de la escuela, su biblioteca y sus alumnos, quienes pasaron de ser usuarios a guardianes de los libros. La "Cronología” es una estrategia seguida para la escritura etnográfica, que aun subyacente, proporciona ilación a la vorágine de acontecimientos que suceden en la vida cotidiana y, esta aparente linealidad, hace que el relato sea accesible y coherente para los destinatarios (Hammersley y Atkinson,1994).

\section{Consentimiento informado}

Reconstruir la historia de la biblioteca implicó, como diría Elliot Eisner en su ya clásico libro El ojo ilustrado, desarrollar la capacidad de ver lo que parecía oculto en el mar de situaciones escolares registradas, y tener el propósito de contar a otros la crónica que interesa, de manera “gráfica y perspicaz” (Eisner, 1998, 41).

La crónica Mente y corazón viajeros tiene un matiz literario, por dos razones. Queremos recuperar la retórica que los relatos etnográficos tenían antaño, y trascender el coto académico para llegar a un público más diverso, interesado en las escuelas rurales y sus bibliotecas. Y queremos devolver la historia a los alumnos de Mundo Nuevo — los de hoy, los de ayer y los de mañana-, y ofrecer a los habitantes de la comunidad un texto accesible y cercano a su experiencia, como producto de investigación “sujeto a contestación” (Rockwell, 2009).

Los alumnos protagonistas y sus madres o abuelas, conocen la primera versión de la historia y dieron su consentimiento para su difusión, con algunas importantes precisiones.

Los nombres de las niñas y los niños que tejieron la historia se conservan como tales, con todas sus letras. Las madres de familia acordaron al respecto porque, en su criterio, presentar a sus hijos con seudónimos sería “como si nunca hubieran existido". Quizá esta decisión fue motivada por la muerte de Juan David, uno de los niños del grupo, mientras se escribía el relato. Una pérdida que dejó desolada a la comunidad y llevó a las madres a defender con determinación el nombre propio de los infantes.

4 Las nueve "versiones ampliadas" a las que hacemos referencia son: "Asamblea infantil”, “Desfile de Lecturas", "Integración Grupo Alfa”, “Círculo de lectura”, “Planeación didáctica”, “Inventario de recursos pedagógicos”, “Proyecto El columpio”, “Proyecto Inauguración de la biblioteca”, "Lectura colectiva del libro Escúchame el corazón” (Archivo etnográfico 2011-2016. Proyecto de investigación: "Prácticas y saberes docentes en escuelas multigrado". Código: P1-EPM-3. Entidad: Veracruz). 
Los nombres de la maestra, la biblioteca y la localidad, también son reales. No son ficticios, como suele suceder en los estudios etnográficos que defienden el anonimato de personas y lugares. En este caso, todas las personas implicadas pidieron conservar la originalidad de los nombres, con el fin de "no opacar las identidades".

Lydia Espinosa coautora de este artículo, era entonces la maestra del grupo y vivió en carne propia la historia que contamos. Durante la escritura aportó su incuestionable experiencia docente, algunos recuerdos preservados en los resquicios de su memoria y el inalterable amor por esos niños y niñas que fueron sus alumnos. El interés paralelo que las tres autoras tenemos por la educación rural, nos ha llevado por sendas compartidas para la producción académica, cuestión sin duda importante. Pero más importante todavía es haber descubierto juntas, a través de la escritura etnográfica, la fertilidad de la colaboración.

\section{APROXIMACIÓN A LAS CONDICIONES BÁSICAS DE UNA BIBLIOTECA VIVA}

A manera de discusión, señalamos algunas condiciones que consideramos indispensables para que la biblioteca sea, efectivamente, un recurso pedagógico "vivo"; es decir, un ámbito escolar en función de los intereses de todos los alumnos y sus aprendizajes en torno a la lengua escrita. Estas condiciones se identificaron en distintas escenas a lo largo del relato, pero trascienden la dimensión local y pueden plantearse como disposiciones necesarias para desarrollar el potencial formativo de las bibliotecas en distintos contextos escolares.

En un estudio sobre el tema, Judith Kalman (2004) adelantó dos requisitos básicos para que las bibliotecas puedan satisfacer intereses y necesidades de los usuarios: disponibilidad y acceso. La disponibilidad se refiere tanto a la presencia física de los materiales impresos, como a la infraestructura para su distribución; mientras que el acceso remite a "las oportunidades para participar en eventos de lengua escrita, situaciones en las cuales el sujeto se posiciona vis-à-vis con otros lectores y escritores, así como a las oportunidades y las modalidades para aprender a leer y escribir.” (Kalman, 2004:25).

En la historia compartida encontramos ambos aspectos. La maestra y las madres de familia procuraron el suministro de materiales desde la reapertura de la escuela. Y el uso creativo del acervo - por ejemplo, la lectura de Escúchame el corazón- proporcionó a niños y niñas experiencias literarias compartidas y el acceso otros mundos y otros lenguajes. Generó, además, la escritura de textos variados con claros propósitos de comunicación que, en el caso del ejemplo, culminó en una relación epistolar con la autora de la novela referida.

La construcción del relato reveló otra condición fundamental para la vitalidad de la biblioteca escolar: la articulación de las actividades y usos bibliotecarios con los propósitos y temas de estudio derivados del currículo vigente. El referente curricular proporciona a los alumnos una guía sobre los contenidos o asignaturas que están estudiando; y establece pautas de actuación pedagógica para los docentes. En este sentido, la multiplicidad de usos de la biblioteca escolar obedece tanto a principios educativos formalmente establecidos, como a las inquietudes y preferencias infantiles. 
Las actividades bibliotecarias que los alumnos del relato desarrollaron no fueron casuales, se orientaron de acuerdo con ciertos principios educativos, por más que en la inmediatez de la vida escolar parecieran azarosas. La lectura en voz alta de parte de la maestra, el contacto con variados materiales literarios, la elaboración de diversos textos de parte de los niños, la búsqueda de palabras en el diccionario, el préstamo de libros a domicilio, entre otras, constituyeron estrategias de enseñanza encaminadas a conseguir uno de los propósitos fundamentales planteados en ese momento para la educación primaria en México: formar alumnos lectores (SEP, 2011).

En un contexto multigrado, la variedad de formas de organización del grupo en torno a la biblioteca constituye una condición necesaria para aprovechar su potencial. Esta organización conlleva la implicación de todos los alumnos en actividades y responsabilidades de acuerdo con su edad, intereses y disposición específica; sus diferentes necesidades educativas y distintos aprendizajes esperados; así como sus particulares avances escolares y niveles de desarrollo. ${ }^{5} \mathrm{La}$ organización del trabajo escolar asociado a la biblioteca se basa en la diversidad del grupo y el potencial de cada uno de los alumnos. Solo así la biblioteca puede convertirse en un recurso vivificante para la enseñanza simultánea en grupos multigrado.

En "Mente y corazón viajeros", los alumnos asumieron funciones bibliotecarias que fueron desde la organización del acervo hasta el control del préstamo de libros, con lo cual se beneficiaron todos: alumnos, maestra, madres de familia, ex alumnos... El compromiso fue gradual y con el tiempo fueron aumentando las responsabilidades, hasta que los alumnos se apropiaron de la biblioteca imponiendo su nombre, que por cierto se conserva en la actualidad. Una tarea de esta envergadura no hubiera sido imposible sin la participación de todos los niños y las niñas en esa empresa colectiva donde desarrollaron autonomía y, al mismo tiempo, aprendieron a tomar en cuenta los intereses del grupo.

Una última condición, no menos importante, se refiere a la participación comunitaria que sostiene y da continuidad a la biblioteca escolar en los territorios rurales. Las estrategias para involucrar a las familias de los alumnos en la activación pedagógica y social de la biblioteca, varían en función de las características culturales y sinergia del territorio. Como lo atestigua la experiencia pedagógica que compartimos, las bibliotecas de las escuelas rurales pueden ser valiosos recursos para formar alumnos lectores y, al mismo tiempo, ofrecer a las comunidades experiencias estimulantes con la lengua escrita, incluso en lugares con severos rasgos de marginación.

En este sentido, las posibilidades pedagógicas que ofrecen las bibliotecas escolares son prácticamente ilimitadas pero, como vemos en el relato, no se dan por el solo hecho de su instalación y equipamiento. Es necesario generar algunas condiciones institucionales y sociales, como las señaladas en este apartado, para potenciar el caudal formativo que conlleva su naturaleza letrada.

\section{UNA REFLEXIÓN FINAL}

Uno de los propósitos de este artículo es abundar la discusión sobre el potencial de las bibliotecas escolares en los contextos rurales. Proponemos una reflexión al respecto desde la cotidiani-

5 Un análisis de las formas de organización del grupo multigrado en la escuela de referencia, se encuentra en Galván y Espinosa (2017). 
dad de una escuela multigrado, su biblioteca, sus lectores y sus usuarios. El camino recorrido a través del relato etnográfico "Mente y corazón viajeros”, proporciona suficientes elementos para responder una pregunta crucial en el cometido: ¿cuál es la contribución de las bibliotecas de escuelas rurales para la formación de la ciudadanía?

Si como afirma Gastán (2014) escuela y sociedad se piensan conjuntamente, y si la biblioteca también es escuela, entonces cabe reflexionar sobre la biblioteca escolar como espacio de posibilidad, en el sentido de que en ella se materialicen ideales democráticos como instruir con equidad, recrear la cultura y compensar desigualdades. Ideales que pueden observarse mediante prácticas pedagógicas que materializan la inclusión de diferentes maneras, como demuestra la historia referida, por ejemplo cuando la maestra se propuso que todos sus alumnos accedieran a los beneficios de la biblioteca y que desplegaran en ella sus particulares capacidades e intereses; o cuando se incluyeron a las madres de los alumnos, quienes disfrutaron también del préstamo bibliotecario y organizaron los libros de tal manera que hasta los más pequeños pudieran alcanzarlos. Más aún, cuando los beneficios de la biblioteca alcanzaron a quienes no tienen hijos en la escuela.

En esta reflexión, importa enfatizar el papel de la maestra en el establecimiento de vínculos entre la biblioteca, el currículum y los aprendizajes de los alumnos. Como se advirtió, la maestra no "ejecuta" mecánicamente los lineamientos del currículum, sino que desde su "acción profesional comprometida” (Gastán, 2014) va tomando decisiones didácticas con base en las propuestas curriculares, el conocimiento de los alumnos, la diversidad de sus intereses y ritmos de aprendizaje, las dinámicas del grupo multigrado y las características de la población rural. La vinculación de estos elementos no es una cuestión meramente técnica, deriva en todo caso de una postura política en educación.

Así entre la biblioteca "Mente y corazón viajeros” y la comunidad veracruzana Mundo Nuevo existen vínculos que permiten no solo imaginar cercanías entre sus poéticos nombres, sino hacer realidad prácticas sociales en donde la lengua escrita actúa como mediadora, poniendo al alcance de la población rural las producciones culturales de otros continentes, y llevando a lugares lejanos las realizadas por los niños y niñas de la propia comunidad. En este sentido, la escuela y su biblioteca constituyen un ámbito social para ejercer el legitimo derecho a producir textos y repensar el mundo (Lerner, 2001); y un campo fecundo para construir valores democráticos y civilidad.

\section{REFERENCIAS}

Bonilla, O., Goldin, D., Salaberria, R. (2014). (Coords). Bibliotecas y escuelas. Retos y posibilidades en la sociedad del conocimiento. Editorial Océano.

Cano, A. e Ibarra, E. (Coords.) (2018). Vulnerabilidad, innovación y prácticas docentes en escuelas multigrado. RIER-UPES- Editora Nómada.

Castán, G. (2014). "La biblioteca escolar y la igualación de oportunidades”. En Bonilla, O., Goldin, D., Salaberria, R. (Coords). Bibliotecas y escuelas. Retos y posibilidades en la sociedad del conocimiento (142). Editorial Océano.

Eisner, E. (1998). El ojo ilustrado. Indagación cualitativa y mejora de la práctica educativa. Paidós educador. 


\section{N V E S T I G A C I O N E S}

Galván, L. y Espinosa, L (2017). Diversidad y prioridades educativas en escuelas multigrado. Estudio de caso en México. Sinéctica. Recuperado de https://sinectica.iteso.mx/index.php/SINECTICA/article/ view/715

Galván Lucila, Solares Diana y Lydia Espinosa (2018). "Recursos pedagógicos para la enseñanza: una noción desde el aula multigrado”. En A. Cano y E. Ibarra (Coords.) Vulnerabilidad, innovación y prácticas docentes en escuelas multigrado (61-86). RIER-UPES-Editora Nómada.

Geertz, C. (2005). La interpretación de las culturas. Gedisa.

Hammersley, M. y Atkinson, P. (1994). Etnografía. Métodos de investigación. Paidós.

Kalman, Judith. (2004). Saber lo que es la letra. Una experiencia de lectura con mujeres en Mixquic. Biblioteca para la Actualización del Maestro. UNESCO/Siglo XXI Editores/SEP.

Lerner, D. (2001). Leer y escribir en la escuela. Biblioteca para la Actualización del Maestro. Secretaría de Educación Pública/Fondo de Cultura Económica.

Pitzorno, B. (2008). Escúchame el corazón. Sabina Editorial.

Robledo, B. (2014). "Una cartografía inconclusa: la realidad de las bibliotecas escolares en nuestros países”. En O. Bonilla, D. Goldin, y R. Salaberria (Coords). Bibliotecas y escuelas. Retos y posibilidades en la sociedad del conocimiento (1-22). Editorial Océano.

Rockwell, E. (2009). La experiencia etnográfica. Historia y cultura en los procesos educativos. Paidós.

Secretaría de Educación Pública. (2011). Plan de estudios 2011. Educación Básica. SEP. 